\title{
A CASE STUDY ON PHYSIOLOGY-BASED DROUGHT SCREENING OF COCONUT WITH SELECTED ACCESSIONS
}

\author{
A. D. Nainanayake ${ }^{1}$ and J. I. L. Morison ${ }^{2}$ \\ ${ }^{1}$ Coconut Research Institute, Lunuwila, Sri Lanka. \\ ${ }^{2}$ Dept. of Biological Sciences, University of Essex, Wivenhoe Park, \\ Colchester, CO4 3SQ, UK
}

\begin{abstract}
Recurrent droughts in Sri Lanka, now becoming increasingly frequent, cause substantial losses in coconut production. Consequently, the development of drought tolerant coconut varieties is an urgent need. Yield is the most reliable parameter to evaluate genotypes for drought tolerance but yieldbased evaluation is a complex and time consuming exercise with a perennial tree crop like coconut.

With the objective of identifying drought tolerant varieties, 40 coconut forms or accessions (forms/acc) in the germplasm collection at Coconut Research Institute of Sri Lanka (CRISL) have been screened. This ongoing investigation gathered information on different types of parameters, and data on a wide range of physiological parameters of adult coconut palms, during an 81-day natural drought was available, along with soil moisture readings in the manure circle. Five contrasting forms/acc (Clovis, Kasagala, Dwarf Green, Cameroon Red Dwarf, and Dwarf x Tall hybrid DT), out of the forty screened, were selected for the present case study to explore the behaviour of some important physiological functions during a drought, their relationships, and the possibility of developing a method for rapid selection of putative drought tolerant coconut palms, based on easily measurable physiological parameters.
\end{abstract}

The response to drought, in terms of physiological parameters, varied in the forms/acc selected for the case study. Clovis was identified as a putative drought tolerant form/acc as it maintained a high rate of photosynthesis and water use efficiency even at the end of the dry spell. Cameroon Red Dwarf was the most drought sensitive. Kasagala showed a degree of drought tolerance, oriented towards survival, with conservation and efficient use of available soil water. However, Kasagala is not likely to be viable as a commercial crop as its low photosynthetic rate due to low stomatal conductance is indicative of low potential productivity. Drought sensitivity 
of DT was at an intermediate level. The assimilation rate of DT was $20 \%$ higher than the mean rate of other forms/acc up to mild levels of water stress, but declined sharply when soil moisture content decreased below 15\%. However, it recovers very quickly on rewetting of the soil with the onset of rains, which enables it to maintain a high overall yield.

The drop in coconut production when soil water is deficient is mainly due to limitations at the stomatal level rather than at the non-stomatal (biochemical) level of the assimilation process, especially in mild to moderate drought conditions. Screening for drought tolerance based on physiological parameters appears to be rapid and promising. Nevertheless, these procedures should be further verified with long-term yield data of more forms/acc before they are widely applied.

Key words:Coconut, drought tolerance, water use efficiency,photosynthesis, stomatal limitation

\section{INTRODUCTION}

Coconut is the most extensive plantation crop in Sri Lanka covering approximately 403,000 ha. It is found in almost all administrative districts of the country except in the few above $750 \mathrm{~m}$ in elevation (Liyanage, 1999; Agriculture Survey, 2002). Coconut is an indispensable component of the Sri Lankan diet and $\approx 70 \%$ of the annual production is consumed locally, as fresh kernel (gratings and milk) or oil extracted from dried kernel. The rest is used in coconut-based industries like desiccated coconut and coconut oil. In addition, a wide variety of products and by-products are manufactured from different parts of the coconut palm viz. kernel, shell, husk, frond, ekel (mid rib), inflorescence and trunk. Hence, the coconut industry makes a sizeable contribution to the national economy and provides food and nutrition to a large segment of the population. It accounts for about $2.0 \%$ of the Gross Domestic Product and $3.4 \%$ of foreign exchange earnings annually (Liyanage, 1999). As a source of food, it provides about 22\% of the calories (second only to the staple rice), and a significant proportion of the proteins in the Sri Lankan diet. However, recurrent droughts in the main coconut growing areas, experienced in recent decades, have led to problems such as loss of employment in coconut-based industries and escalation of coconut prices affecting local consumers (Nainanayake and Morison, 2004). In some years, the failure of monsoon rains extend the normal dry season of 3-4 months to 5-6 months, resulting in heavy yield losses and sometimes, in severely affected areas, deaths of adult coconut palms (Jayasekara et al., 1993). Consequently, in some dry years, annual national production 
decreased by about 1,000 million nuts compared to the production in year 2000 , which was preceded by a good year (1999) with well distributed rainfall exceeding 2,200 $\mathrm{mm}$ (CDA, 2000). The development of drought tolerant coconut varieties has been recognized in the mid-1990s as an important and urgent area of research (Perera et al., 1996). With worsening climatic conditions since, the need for drought tolerant varieties has become critical.

Yield is the most integrative and commonly used parameter to evaluate genotypes for their tolerance to drought or any other environmental stress (Wachira et al., 2002). However, yield-based evaluation is a complex and time consuming exercise with a perennial tree crop like coconut which has a long generation period of takes about 15 years for yields to stabilize, and the fruits have a long development period taking about one year from the opening of an inflorescence for the nuts to mature. Setting of button nuts, enlargement of nuts and development of nut water and kernel takes place sequentially at different times of this year-long maturation period (Ranasinghe et al., 2003). The impact of a drought on yield, especially on the different nut components, will therefore vary with the development stage exposed to the drought. Hence, the development of an alternative methodology for rapid selection of drought tolerant palms is most desirable.

The coconut germplasm collection at CRISL commenced in 1961 (Liyanage, $1961 \mathrm{a} \& \mathrm{~b}$ ) as a traditional varietal collection, and was extended further as a systematic collection in 1984 (Wickramaratne, 1984). Forty forms or accessions (forms/acc) in this collection have been screened for drought tolerance. While different techniques were employed in this screening there was greater emphasis on physiological parameters such as the rate of photosynthesis $(A)$ and instantaneous water use efficiency $\left(\omega_{\text {inst }}\right)$ as reference parameters. As the investigation covered a wide range of physiological parameters of adult coconut palms, under natural drought conditions, it provided an opportunity to explore the behaviour of some important physiological functions under drought, their relationships and the possibility of using them to screen coconut genotypes for drought tolerance. Five of the 40 form/acc tested were selected for this study which endeavours to develop a method for rapid selection of putative drought tolerant coconut palms, based on easily measurable physiological parameters instead of the yield. 


\section{MATERIALS AND METHODS}

\section{Planting material}

Five forms/acc, Dwarf Green $(D G)$, Cameroon Red Dwarf $(C R D)$, Clovis $(C L)$, Kasagala $(K S)$ and the hybrid, Dwarf x Tall $(D T)$, were selected for this study out of the 40 forms/acc tested. $D G$ and $C R D$ were two different forms of the variety nana (dwarfs), which is believed to be sensitive to drought. Of the two dwarfs, $C R D$ is thought to be more sensitive to drought while $D G$ produces high yields, under favourable conditions. Both $C L$ and $K S$ belong to the variety typica (talls). $C L$ has a pacific origin (Philippines) and is believed to have been introduced to Sri Lanka a few decades ago and acclimatized to the Sri Lankan climatic conditions. Generally, $C L$ is comparatively less affected by droughts. The accession $K S$ is from selfpollinated off-spring of an adult coconut population which survived a severe drought in the southern part of Sri Lanka, about 15 years ago. Finally, the variety Dwarf x Tall $(D T)$ is the hybrid developed using $D G$ and selected Tall palms as parents and is generally believed to be drought sensitive. These germplasm accessions are conserved in an ex situ gene bank at Pottukkulama Research Station (PRS), Pallama, Sri Lanka and are approximately 15 years old. Planted in a $7.8 \times 7.8 \times 7.8 \mathrm{~m}$ triangular planting system the palms have been regularly fertilized and managed according to practices recommended by the CRISL (Liyanage, 1999). The genebank was sited in flat terrain on a highly suitable Madampe series deep sandy loam soil (Land suitability class S1) (Somasiri et al., 1994).

Six palms, adjacent to each other, of each form/acc, were monitored over 14 weeks, from January to April 2003, the first 11 weeks being the drought period. Physiological parameters and the soil moisture content were recorded at two-weekly intervals. As the germplasm collection was not replicated a completely randomized design was used. The uniformity of the land, the age of palms and their management justified the basic data analytical techniques applied.

\section{Soil moisture content}

Soil moisture content $(\theta)$ was determined once every 14 days during the natural drought that occurred from January to April in 2003. Soil core samples were collected, $1 \mathrm{~m}$ from the base of the palm, at three different depths viz. $50 \mathrm{~cm}, 100 \mathrm{~cm}$ and $150 \mathrm{~cm}$. Soil moisture content was determined gravimetrically using a complete lump of soil of approximately $200 \mathrm{~cm}^{3}$ at each depth. Two sets of soil core samples were taken, near two of the six 
palms, in each form/acc plot. The mean soil moisture content $\left(\theta_{\text {mean }}\right)$ was calculated as the average of $\theta$ at 3 depths. As the $80 \%$ of the coconut root system exploits the top $150 \mathrm{~cm}$ of the soil profile, the calculated $\theta_{\text {mean }}$ was assumed as the average moisture content across the soil profile. Also, the $\theta_{\text {mean }}$ was assumed to be applicable to all six palms in the form/acc plot, as the six palms were adjacent to each other and located in the middle of the block.

\section{Physiological parameters}

The physiological measurements and leaf compound assays were done simultaneously with the soil sampling. All physiological measurements were conducted on the ninth leaf, counting from top. The ninth leaf has been identified as being representative of the middle whorl (leaf numbers 9-14), which is considered as the most active physiologically (Braconnier and Bonneau, 1998). The rate of photosynthesis $\left(A, \mu \mathrm{mol} \mathrm{m} \mathrm{m}^{-2} \mathrm{~s}^{-1}\right)$, stomatal conductance $\left(g_{s}, \mathrm{~mol} \mathrm{~m}^{-2} \mathrm{~s}^{-1}\right)$, the rate of transpiration $\left(E, \mathrm{mmol} \mathrm{m}^{-2} \mathrm{~s}^{-1}\right)$ and intercellular $\mathrm{CO}_{2}$ concentration $(\mathrm{Ci}, \mathrm{ppm})$ were measured using the gas exchange technique in a closed-system portable photosynthesis system ( $\mathrm{Li}$ 6200 , LI-COR Inc., USA); and the instantaneous water use efficiency ( $\omega_{\text {inst }}$, $\mu \mathrm{mol} \mathrm{CO} \mathrm{Col}^{-1} \mathrm{H}_{2} \mathrm{O}$ ) was calculated as the ratio of $A / E$. Leaf water potential $(\Psi, \mathrm{MPa})$ was measured on entire leaflets with intact midrib (ekel) observing the return of water to the cut surface of the ekel using a Scholander type pressure chamber (Soil Moisture Equipment Corporation, Santa Barbara, CA, USA).

The software package, Statistical Analysis System (SAS Release 8.2, SAS Institute Inc., USA) was used for ANOVA and correlation analyses.

\section{RESULTS}

\section{Soil moisture content}

At the onset of the drought, the soil moisture content at $50 \mathrm{~cm}\left(\theta_{50}\right)$ was substantially lesser than at the lower depths, $100 \mathrm{~cm}\left(\theta_{100}\right)$ and $150 \mathrm{~cm}\left(\theta_{150}\right)$ (Fig. 1a, b \& c). At each depth, the moisture contents in the different forms/acc plots were similar. The $\theta_{50}$ averaged across all forms/acc was $29.8 \%$ while $\theta_{100}$ and $\theta_{150}$ were $33.1 \%$ and $37.9 \%$ respectively.

At the end of the drought, the soil had dried up considerably with the moisture content about $11.0 \%$ at $50 \mathrm{~cm}$ and $100 \mathrm{~cm}$; and $14.4 \%$ at $150 \mathrm{~cm}$. The pattern of soil moisture depletion brought about by different genotypes was similar at the different soil depths. 
When upper soil layers dry out, coconut roots absorb water from deeper layers as over $80 \%$ of the root system exploits the top $150 \mathrm{~cm}$ of the profile (Vidhana Arachchi, 1998). Hence, the mean soil moisture content within the entire soil profile up to $150 \mathrm{~cm}\left(\theta_{\text {mean }}\right)$ was taken as an appropriate measure of the soil moisture status of a form/acc plot. At the onset of the drought, $\theta_{\text {mean }}$ across the five forms/acc was about $33.4 \%$ with the difference between forms/acc being less than $2.0 \%$ (Fig. 1d). Towards the latter part of the drought, differences between forms/acc were substantial. This was reflected in significant genotypic variations in the lowest or minimum soil moisture content $\left(\theta_{\text {min }}\right)$ recorded at the end of the drought (Fig. 2a). 

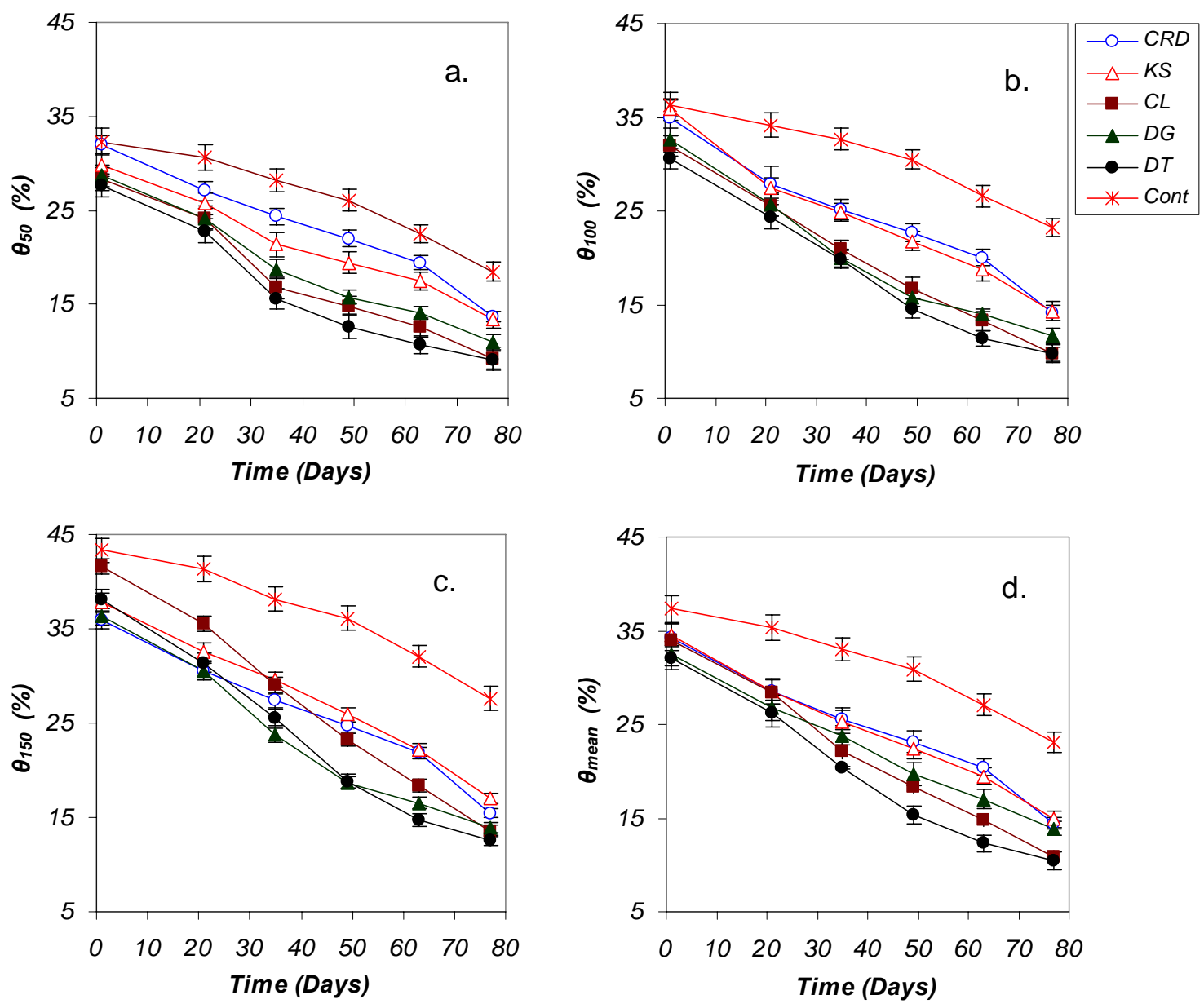

Fig. 1. Mean soil moisture content at the depth of (a) $50 \mathrm{~cm}\left(\theta_{50}, \%\right)$ (b) 100 $\mathrm{cm}\left(\theta_{100}, \%\right)(\mathrm{c}) 150 \mathrm{~cm}\left(\theta_{150}, \%\right)$ and (d) mean of entire $150 \mathrm{~cm}$ soil profile $\left(\theta_{\text {mean }}, \%\right)$ of forms/acc plots during the drought.

(Control $-\theta_{\text {mean }}$ measured in an open space without coconut but with the natural grass cover as in other areas; SE of the mean is indicated by vertical bars) 

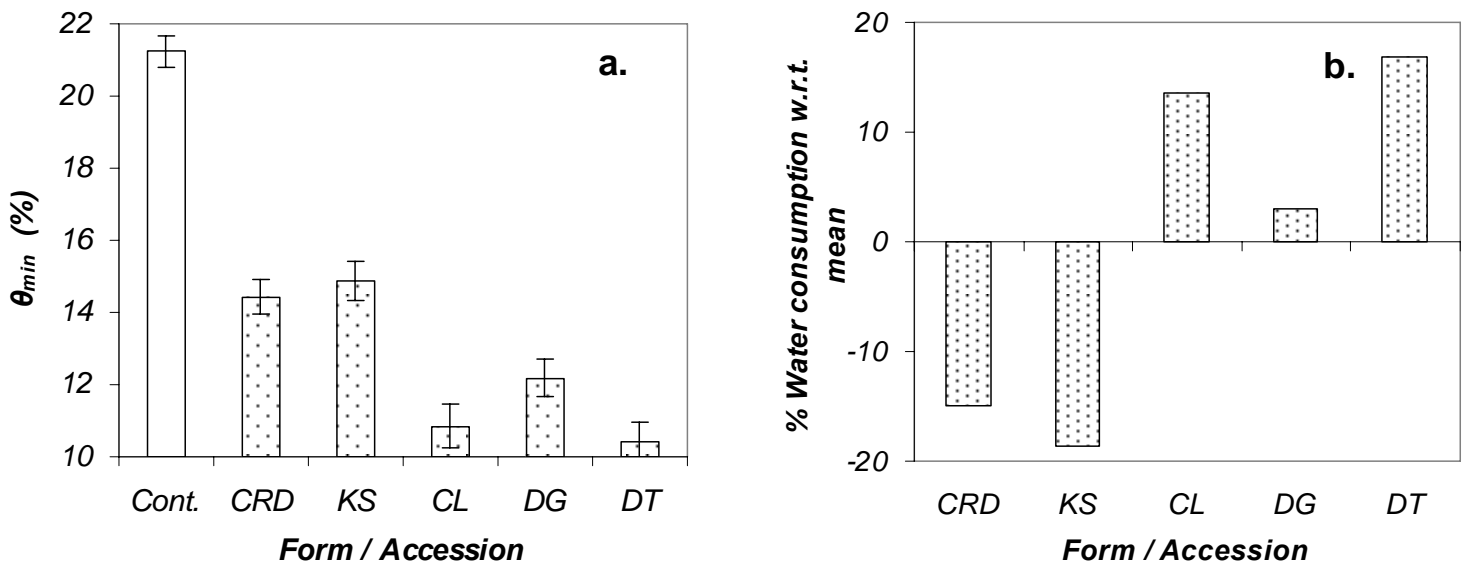

Fig 2 (a) The minimum soil moisture content $\left(\theta_{\min }\right)$ observed at the end of the drought in the forms/acc plots and (b) water consumption as a percent of the mean consumption across forms/acc.

At the end of the drought, $C L$ and $D T$ plots recorded the lowest $\theta_{\min }, 10.8 \%$ and $10.4 \%$ respectively indicative of a high consumption of water, $D G$ consumed less water and recorded a $\theta_{\min }$ about $12.0 \%$, and $C R D$ and $K S$ even less recording around $15.0 \%$.

$C R D$ and $K S$ consumed about $20.0 \%$ less, and $C L$ and $D T$ consumed about $15.0 \%$ more water than the mean consumption of the forms/acc (Fig. 2b). Consequently, there was more water in the soil of $C R D$ and $K S$ plots at the end of the drought.

\section{Gas exchange parameters}

At the beginning of the drought, the highest rate of photosynthesis $(A)$, which was $20 \%$ higher than the forms/acc mean $(\mathrm{P}<0.01)$, was recorded in $D T$, and the lowest in $C R D$ and $K S$ (Fig. 3a). The rate of photosynthesis of all forms/acc declined with the progress of drought. However, the rate of decline (gradient of the linear regression) varied: high in $D T, D G$ and $C R D$ and lowest in $C L$, which maintained a significantly higher $A, \approx$ thrice the forms/acc mean $(\mathrm{P}<0.01)$, at the end of the drought. Differences between forms/acc were more conspicuous when $A$ was plotted against the $\theta_{\text {mean }}$ where $C L$ showed a significantly higher $A$ at a low $\theta_{\text {mean }}$ of $\approx 11.0 \%$ than $C R D$ and $K S$ at $15.0 \% \theta_{\text {mean }}$ (Fig. 3b). 

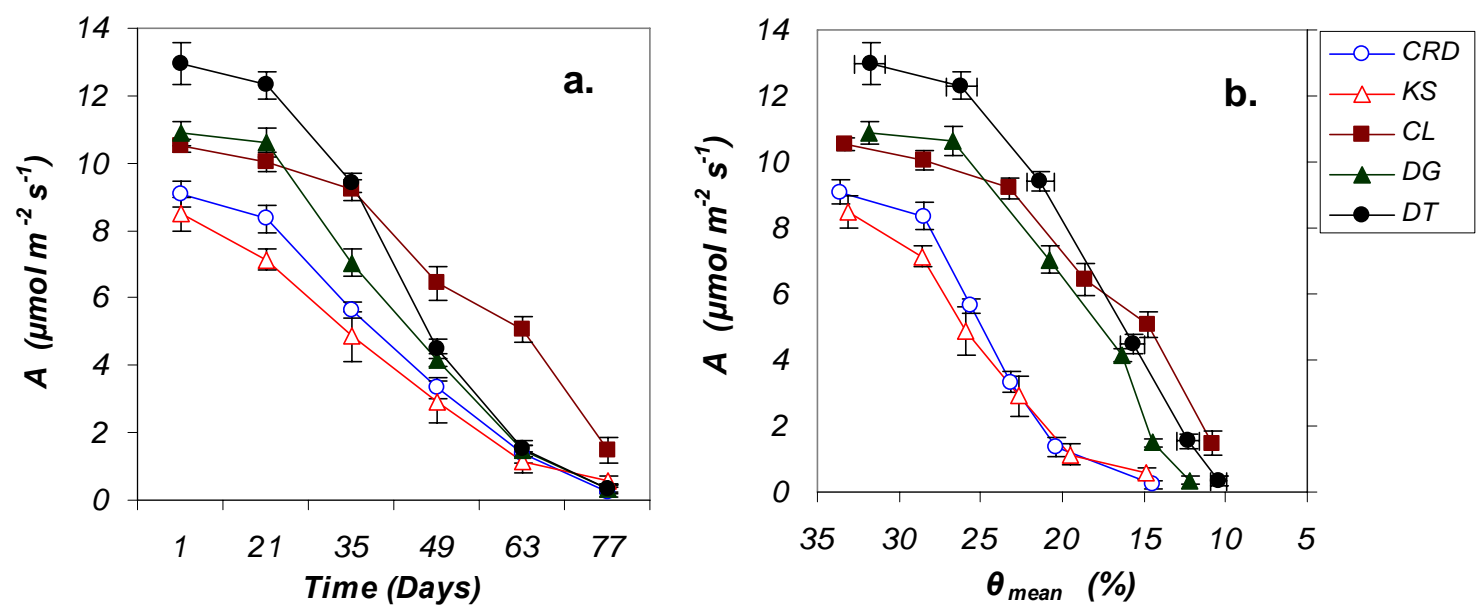

Fig. 3 (a) Mean rate of photosynthesis $\left(A, \mu \mathrm{mol} \mathrm{m} \mathrm{m}^{-2} \mathrm{~s}^{-1}\right)$ of different forms/acc of coconut exposed to a 81-day drought period and (b) the effect of soil moisture content $\left(\theta_{\text {mean }} \%\right)$ on $A$.

At the onset of the drought, the highest stomatal conductance $\left(g_{s}\right)$ was recorded in $D T$ and $D G(\mathrm{P}<0.01)$ which declined rapidly with the progress of the drought (Fig. 4a). On the other hand, $K S$ and $C R D$ which recorded the lowest $g_{s}(\mathrm{P}<0.01)$ at the beginning, declined at a much slower rate, and $C L$ which declined at the slowest rate maintained a stomatal conductance $\approx 40 \%$ higher than the forms/acc mean, at the end of the drought. A more or less similar pattern was observed for the rate of transpiration $(E)$, except for $K S$ recording a significantly lower $E$, at the inception of the drought (Fig. $4 \mathrm{~b}$ ). 

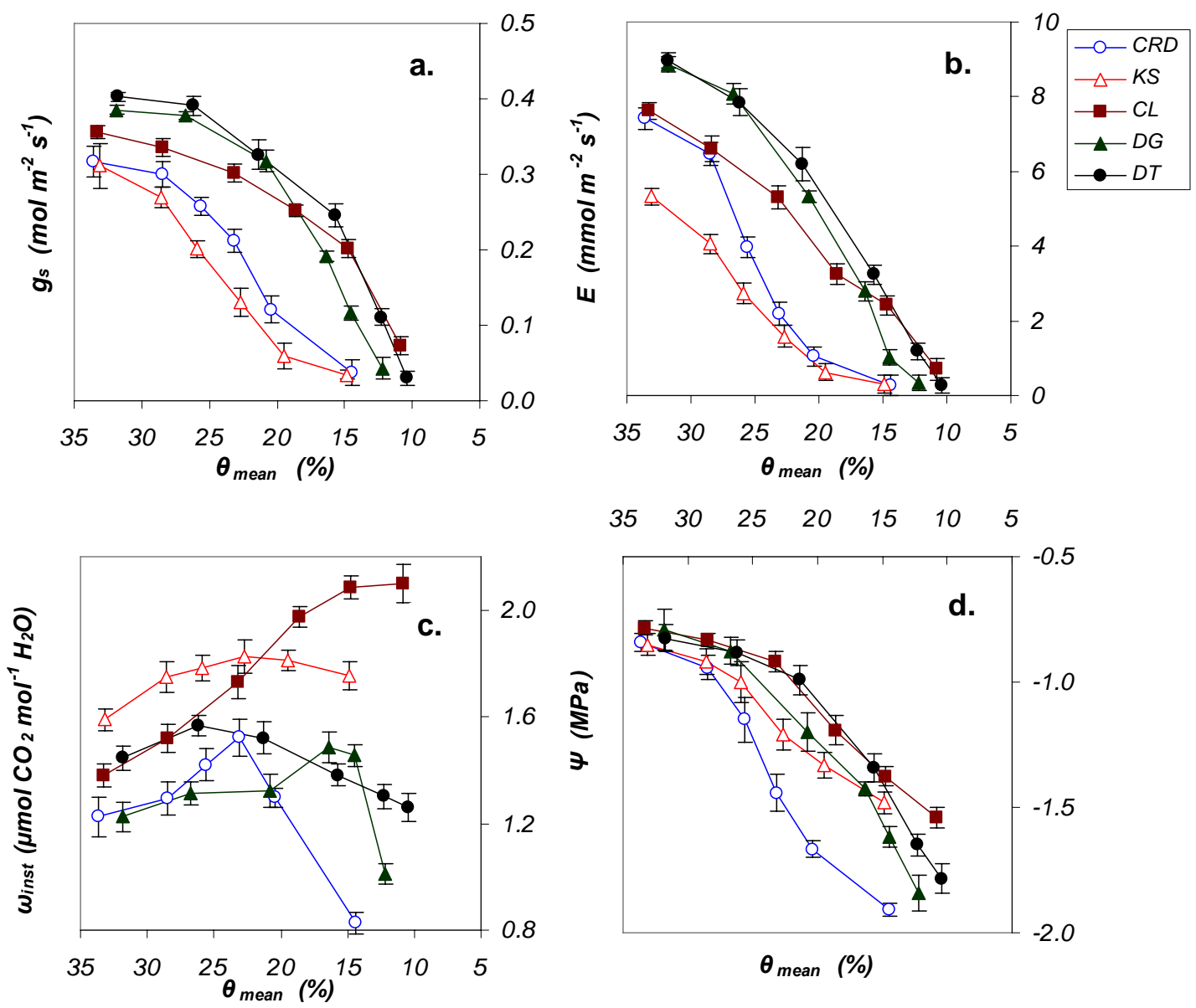

Fig. 4 (a) Mean stomatal conductance $\left(g_{s}, \mathrm{~mol} \mathrm{~m}^{-2} \mathrm{~s}^{-1}\right)$, (b) mean rate of transpiration $\left(E, \mathrm{mmol} \mathrm{m}^{-2} \mathrm{~s}^{-1}\right),(\mathrm{c})$ mean instantaneous water use efficiency $\left(\omega_{\text {inst }}, \mu \mathrm{mol} \mathrm{CO}_{2} \mathrm{~mol}^{-1} \mathrm{H}_{2} \mathrm{O}\right)$ and $(\mathrm{d})$ mean leaf water potential $(\Psi, \mathrm{MPa})$ of different forms/acc of coconut in response to the declining soil moisture content $\left(\theta_{\text {mean }} \%\right)$.

At the inception of the drought, instantaneous water use efficiency $\left(\omega_{\text {inst }}\right)$ was highest in $K S(\mathrm{P}<0.01)$ followed by $C L$ and $D T$, and was lowest in $C R D$ and $D G$ (Fig. 4c). All forms/acc showed an increase in $\omega_{\text {inst }}$ at initial stages of the drought. However, as the drought progressed the $\omega_{\text {inst }}$ declined rapidly in $C R D$ and $D G$ when $\theta_{\text {mean }}$ fell below $25 \%$ and $15 \%$ respectively, and declined at a slower rate in $D T$ when $\theta_{\text {mean }}$ fell below $28 \%$, while there was a gradual increase of $\omega_{\text {inst }}$ in $K S$ with only a slight drop towards the end of the drought when $\theta_{\text {mean }}$ was around $15 \%$. $C L$ was exceptional with $\omega_{\text {inst }}$ increasing at a rapid rate until the end of the 81-day drought when $\theta_{\text {mean }}$ fell to as low as $11 \%$. This indicates that though $C L$ maintained a stomatal conductance rate $\left(g_{s}\right), 40 \%$ higher than the mean at the end of the drought (Fig. 4a), which 
enhanced both $A$ and $E$, the enhancement of $A$ was more pronounced. Significantly lower leaf water potential of $C R D, D G$ and $D T$ towards the end of the drought is consistent with the reduction of $\omega_{\text {inst }}$, while the maintenance of a higher leaf water status in $C L$ and $K S$ reflects their capacity for higher $\omega_{\text {inst }}$ even at the end of the drought (Fig. 4d).

Substantial differences were observed in $\theta_{\text {mean }}$ among forms/acc as the drought progressed. This suggests it would be more rational to compare the forms/acc at a constant, low level of $\theta_{\text {mean }}$ say, $15 \%$. At this soil moisture level of $15 \%$, the rate of photosynthesis $(A)$ of $C L$ was the highest (twice the forms/acc mean) and $C R D$ and $K S$ were the lowest (Fig 5a). DT maintained a substantial rate of $A\left(3.8 \mu \mathrm{mol} \mathrm{m} \mathrm{m}^{-2}\right)$ at $15 \% \theta_{\text {mean }}$ but declined sharply with further decreases of $\theta_{\text {mean }}$ (Fig. 3b). The pattern was more or less similar for both $g_{s}$ and $E$ (Fig. 5b \& 5c respectively) where both $C L$ and $D T$ maintained substantially higher rates over the other forms/acc. Leaf water potential was notably low in $C R D$ even at $15 \% \theta_{\text {mean }}$ (Fig. $5 \mathrm{~d}$ ) which possibly resulted in a low $\omega_{\text {inst }}$ but the reverse was observed in $C L$ (Fig. 5e); the differences between the other forms/acc were not substantial.
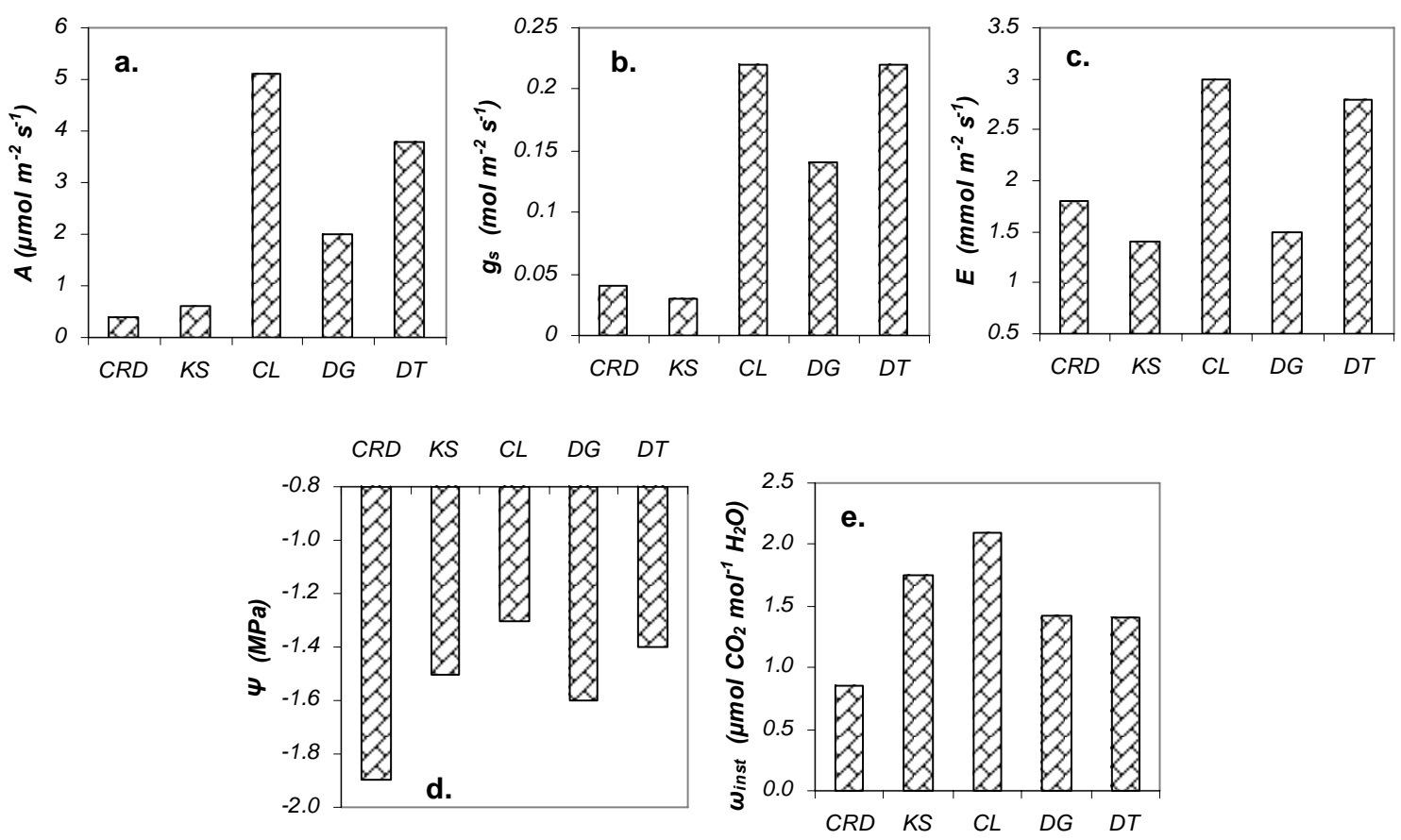

Fig. 5 Rates of physiological parameters $A, g_{s}, E, \Psi$ and $\omega_{\text {inst, }}$ at a $\theta_{\text {mean }}$ of $15 \%$, at $5 \mathrm{a}, \mathrm{b}, \mathrm{c}, \mathrm{d}$, and e respectively. 


\section{Relationships between parameters}

Progressive decrease of $\theta_{\text {mean }}$ during a prolonged drought triggers cascades of physiological and biochemical events. Correlation analyses were performed to study the relationships between $\theta_{\text {mean }}$ and the physiological parameters whose response to depleting $\theta_{\text {mean }}$ was variable. The reduction of $A$ in response to depleting $\theta_{\text {mean }}$ was well explained by the good correlation $\left(\mathrm{r}^{2}>\right.$ $0.91)$ between them in all five forms/acc (Table 1). In addition, correlations between parameters such as $\theta_{\text {mean }}, \Psi, g_{s}$ and $A$ suggest that a sequence of physiological events occur in coconut palms exposed to depleting soil moisture. As observed in many annuals, declining $\theta_{\text {mean }}$ restricts water absorption which affects the internal water status and forces the coconut palm to conserve water and use it economically. As a consequence of the reduced $\Psi$, a partial or full closure of stomata takes place resulting in a reduction of $g_{s}$ which is reflected in the good correlation observed between $\Psi$ and $g_{s}(\mathrm{r}>0.96)$, in all forms/acc. Moreover, chemical signals originating in the roots, in response to moisture stress, may activate and/or synthesize abscisic acid (ABA) to induce stomatal closure. The 3 to 4 fold increase of xylem ABA content over the drought period (Fig. 6) suggests that ABA has a role in stomatal regulation in coconut under moisture stress.

Table 1 Correlation coefficients $\left(\mathrm{r}^{2}\right)$ between physiological parameters in different coconut forms/acc during the drought

\begin{tabular}{lccccc}
\hline Form/acc & $\theta_{150}$ vs. $\Psi$ & $\Psi$ vs. $g_{s}$ & $g_{s}$ vs $A$ & $A$ vs $C_{i}$ & $\theta_{150}$ vs. $A$ \\
\hline$C R D$ & 0.97 & 0.98 & 0.95 & 0.91 & 0.95 \\
$K S$ & 0.98 & 0.99 & 0.99 & 0.94 & 0.97 \\
$C L$ & 0.96 & 0.97 & 0.99 & 0.90 & 0.93 \\
$D G$ & 0.97 & 0.96 & 0.95 & 0.92 & 0.96 \\
$D T$ & 0.95 & 0.96 & 0.93 & 0.93 & 0.91 \\
\hline
\end{tabular}




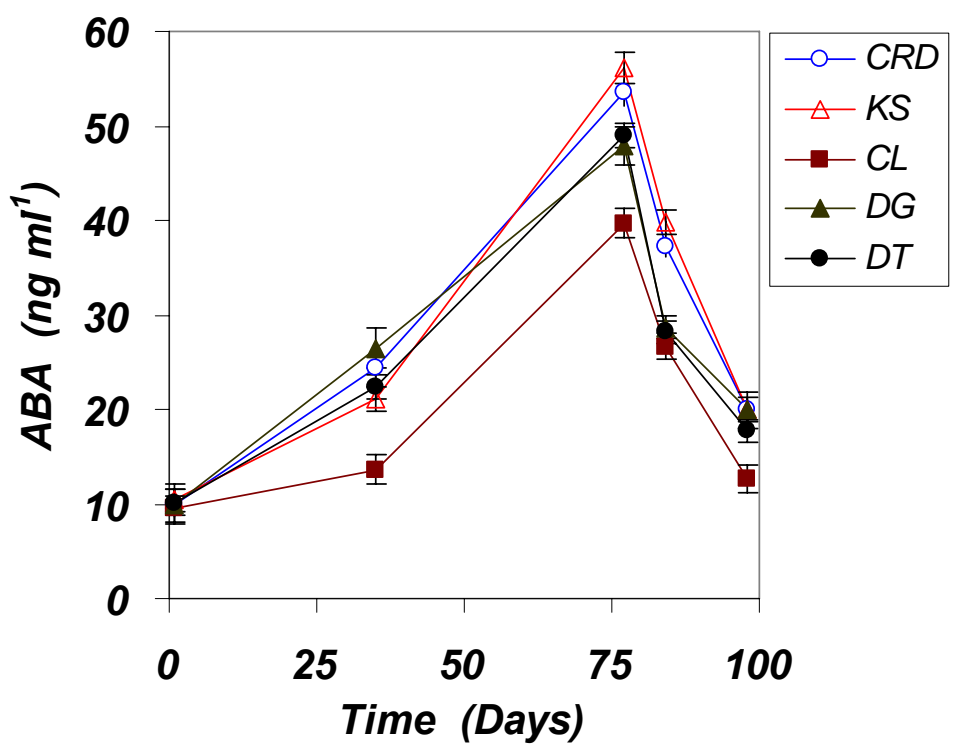

Fig. 6 Xylem abscisic acid content in leaves $\left(A B A, \mathrm{ng} \mathrm{ml}^{-1}\right)$ of different forms/acc of coconut exposed to an 81-day drought period followed by rains.

If $g_{s}$ was controlled by chemical signals originating in the roots, a significant positive correlation between $g_{s}$ and $\Psi$ could be expected. If chemical signals are in operation, then $g_{s}$ will decline even without a reduction of $\Psi$. Taking these into consideration, the likely sequence of events are as follows. With the onset of water stress, chemical signals that trigger an increase in ABA concentration, induce stomatal closure and reduce $g_{s}$. The reduced absorption of water by the root system reduces $\Psi$. Therefore, the reduction of $\Psi$ is independent of the reduction of $g_{s}$. As $\Psi$ and $g_{s}$ are reduced simultaneously, although by different mechanisms, a significant positive correlation could be observed between $g_{s}$ and $\Psi$. The significant positive correlation $\left(\mathrm{r}^{2}>0.93\right)$ between $A$ and $g_{s}$, along with reduced $C_{i}\left(\mathrm{r}^{2}>0.90\right)$ indicate a significant stomatal limitation of photosynthesis in a water-stressed coconut palm.

\section{DISCUSSION}

The dry spell encountered in the present study was not among the longest dry spells, nor was the $\theta_{\text {mean }}$ among the lowest soil moisture levels recorded, in the area where the experiment was conducted. However, the moisture depletion was sufficient to distinguish varietal differences at early stages of the drought. 


\section{Stomatal and non stomatal limitations}

Stomatal conductance decreased markedly in $K S$ and $C R D$ at a relatively early stage of the drought even when $\theta_{\text {mean }}$ was around $25 \%$ (Fig. 4a), indicating early closure of stomata for the conservation of water. Thus, the restriction of $\mathrm{CO}_{2}$ uptake at the stomatal level could be the primary cause for rapid reductions in $A$ in both $K S$ and $C R D$ (Fig. 3). However, $C L$ with a marginally higher $g_{s}$ at the beginning of the drought, showed a gradual decline with the decrease in $\theta_{\text {mean }}$ and maintained a substantially higher $g_{s}$ $\left(0.08 \mathrm{~mol} \mathrm{~m}^{-2} \mathrm{~s}^{-1}, 60 \%\right)$ than other forms/acc even when $\theta_{\text {mean }}$ was close to $10 \%$. The higher $A$ observed in both $D T$ and $D G$ at the very beginning of the dry spell may be due to this slightly higher $g_{s}$ which would have facilitated more efficient gaseous exchange at stomatal level. This could be an inherent character of $D G$, which has been also transferred to $D T$, and perhaps enhanced in $D T$ due to hybrid vigour ( $D G$ is one of the parent palms of $D T$ ). However, their quick response to depleting soil moisture was to be expected on account of the rapid reduction of $g_{s}$ observed when $\theta_{\text {mean }}$ fell below $20 \%$ and $15 \%$ in $D G$ and $D T$ respectively (Fig. 4 a).

The response pattern of $g_{s}$ to $\theta_{\text {mean }}$ was clearly reflected in that of $E$, in all forms/acc (Fig. 4a and b) and indicated a good correlation between the two parameters during the drought. The good correlation observed between $g_{s}$ and $A$, as well as $A$ and $C_{i}$ (Table 1) suggest that, in coconut palms, stomatal limitations to the assimilation process during the early and mid stages of the drought was more pronounced than non-stomatal or biochemical limitations. As there were no differences in biochemical parameters such as total soluble sugars and leaf proline pool (data not presented here) (Nainanayake, 2004) biochemical changes are unlikely in the early stages of the drought. This is further supported by the quick recovery seen in most forms/acc with the onset of the rains. The available data were not sufficient to reach any conclusions on osmotic adjustment in coconut under soil moisture deficits.

Results of this study suggest that the decrease in the assimilation rate in coconut, during a period of moisture stress, is due largely but not exclusively, to stomatal limitations rather than non-stomatal (biochemical) limitations. This may account for the lack of significant differences or correlations between biochemical parameters and other parameters monitored, in the range of moisture stress encountered in this study. The biochemical pathways may be triggered in response to moisture stress during a more severe drought when tissue water potential is reduced substantially on exposure to markedly low soil moisture levels. 


\section{Consistency with previous findings and drought screening criteria}

$K S$ was included in the germplasm conservation pool as its parent population had withstood severe droughts and that it is likely to be drought tolerant. Similarly, $C L$ was selected on the basis of some morphological characters such as large nut size and thick kernel coupled with its ability to withstand drought. The emergence of these forms/acc as being drought tolerant in this study shows that criteria based on physiological parameters are consistent with the general criteria employed about two decades ago to identify putative drought tolerant accessions. Forms/acc with a high water use efficiency combined with a high rate of assimilation are of great value for a commercial crop where not only survival but also production is important. The tendency of $K S$ for low productivity, which may be due to reduced $A$ with decreasing soil moisture, brings in to question the suitability of $K S$ as a commercially viable genotype even though it showed high water use efficiency.

Although $D T$ was not as drought tolerant as $C L$, it had the highest rate of photosynthesis under well-watered, favourable conditions, with above average $A$ in pre and early stages of the drought until $\theta_{\text {mean }}$ declined to about $18 \%$. Thus, $D T$ would have a greater potential for higher yields in wet and intermediate zones of the country where water shortages are not frequent or minimal or when cultivated under irrigation. This is supported by previous records of $57 \%$ higher nut yield (nuts/ha/year) and $42 \%$ higher copra yield (MT/ha/year) in $D T$ over the widely cultivated Tall varieties during a six year period from 1996-2001 in 7 experimental sites maintained by CRISL (Everard, 2002). As those sites were located in a range of different soils and agro-ecological regions (e.g. loamy soil in the wet intermediate zone; deep latosol in the dry zone; lateritic gravel in the wet zone; sandy clay loam in the dry intermediate zone; clay loam in the wet intermediate) and the trial covered both wet and dry periods, the above figures are a good reflection of the average yield performance of $D T$ in contrasting environments. For instance, at the Thammanne site, a deep latosol in the dry zone, $D T$ yielded $83 \%$ more nuts and $63 \%$ more copra than the tall variety (Everard, 2002). The higher rate of $A$ observed in $D T$ is consistent with these high yields. Although $D T$ was adversely affected by drought, it responded quickly to improved $\theta_{\text {mean }}$ with the onset of rains and regained the initial rates of $A$. This is an important feature in a commercial crop. However, there is a general belief among Sri Lankan growers that $D T$ is highly susceptible to drought. This has limited its cultivation to a home garden scale. There are no large scale plantations of $D T$ even in the wetter parts of the main coconut growing area, except for a few experimental sites of CRISL. But, according to the results of these experiments, the productivity of $D T$ is likely to be very high 
in the wet and intermediate parts of the country. Although DT was commercially released in 1965 as an improved coconut hybrid variety it has remained under exploited to date.

$C R D$ which had been included in the germplasm collection as an exotic dwarf form showed its high sensitivity to drought in this study. Symptoms such as drooping leaves, decrease in leaf production and nut setting observed in $C R D$ even in the early stages of a drought, confirmed its drought susceptibility.

\section{Limitations of physiology based evaluation}

The relationship between crop yields and physiological parameters such as the rate of photosynthesis is still a matter of debate (Lawlor, 1995; Medrano et al., 1995). However, the need for high rates of photosynthesis to attain high yield levels has been emphasized by Mann (1999). Lawlor (1995) argued that although net photosynthesis is the driving force for all plant growth, the total dry matter production is determined by the integrated result of numerous canopy processes and factors such as primary light interception, leaf area index, canopy architecture and leaf area duration. Since these parameters are not linearly related and that photosynthesis is less sensitive to environmental changes than leaf area development, Lawlor (1995) argued that assessing crop productivity based on variation in net photosynthesis would not be accurate. Lawlor points to light interception varying with leaf area expansion over time. While this variation in leaf area is especially applicable in arable crops, the adult coconut canopy hardly varies over time and maintains a fairly constant leaf area throughout the year except in extreme drought conditions. Even then, it is the older leaves in the lower whorl, which are generally fully shaded and make little or no contribution to assimilation, that are shed. Thus the changes in leaf area in coconut do not influence dry matter production as in annuals, which have a high leaf turnover. Moreover, recent experiments have shown good correlations between photosynthesis and final yield thus providing evidence to support genotype selection based on photosynthetic capacities. Mitchell et al., (1999) reported an average increase of $50 \%$ in canopy photosynthesis, in a genotype of spring wheat, grown in seven sites in Germany, the UK, Ireland, Belgium and the Netherlands, which resulted in an average increase of $35 \%$ in grain yield. A more recent analysis revealed a parallel increase in canopy photosynthesis and yield, under elevated $\mathrm{CO}_{2}$, in soybean (Ainsworth et al., 2002). Based on a series of findings in elevated $\mathrm{CO}_{2}$ experiments, Long et $a l .$, (2006) inferred that yield is either source driven or source-sink activity is coordinated in such a way that increase or maintenance of source (rate of 
photosynthesis) would stimulate the sink capacity (yield). Thus more encouraging evidence is emerging from different crop species in favour of physiology (especially assimilation) based selection of genotypes. However, it is imperative to re-evaluate and confirm these findings using long-term yield data to develop more precise screening procedures.

\section{CONCLUSIONS}

The response to drought, in terms of physiological parameters, varied in the forms/acc of coconut tested. $C L$ was identified as being more drought tolerant than the other forms/acc based on physiological parameters such as $A$ and $\omega_{\text {inst }}$ measured during the drought. CRD was the most drought sensitive. $D T$ showed an intermediate level of sensitivity, though its physiological processes were substantially affected at the end of the drought. Its inherent characteristics of a high photosynthetic rate in non-limiting or mild water stress conditions, and ability to make a quick recovery from severe moisture stress when the rains come, indicate its potential for high productivity in the wet or intermediate zones where water shortages are not frequent or prolonged. $K S$ possessed a certain degree of drought tolerance with the tendency to conserve water from the very early stages of the drought, possibly an adaptation directed at survival. $K S$ is not likely to be viable as a commercial crop due to its low productivity but should be ideal breeding material for drought tolerant hybrids. Reduced productivity in coconut when soil water is deficient, is mainly due to limitations at the stomatal level rather than at the non-stomatal (biochemical) level of the assimilation process, in mild to moderate drought conditions. Screening for drought tolerance based on physiological parameters is rapid and promising. Nevertheless, these procedures should be further verified with long-term yield data before they are widely applied.

\section{ACKNOWLEDGEMENTS}

This study was funded by the Coconut Cess Fund of the Government of Sri Lanka. Authors sincerely thank Dr. (Mrs.) C. Jayasekara, Director, CRISL and Mr. J M D T Everard, Deputy Director (Research), CRISL for facilitating this study and the staff of the Plant Physiology Division for their assistance in field and laboratory work. 


\section{REFERENCES}

Ainsworth, E. A., Davey, P. A., Bernacchi, C. J., Dermody, O.C., Heaton, E.A., Moore, D.J., Morgan, P.B., Naidu, S.L, Yoo, H., Zhu, X-G, Curtis, P.S. and Long, S.P. (2002). A meta analysis of elevated $\left[\mathrm{CO}_{2}\right]$ effects on soybean (Glycine max) physiology, growth and yield. Global change Biology 8: 695-709.

Braconnier, S. and X. Bonneau (1998). Effect of chlorine deficiency in the field on leaf gas exchanges in the PB121 coconut hybrid. Agronomie, 18: $563-572$.

CDA (2000). Sri Lanka coconut statistics. Coconut Development Authority, Sri Lanka.

Agriculture Survey (2002). Department of Census and Statistics, Sri Lanka.

Everard J.M.D.T. (2002). Report of the Genetic and Plant Breeding Division. In Annual Report for 2002. Eds. Jayasekara C, Somasiri L.L.W. 5177. Coconut Research Institute, Sri Lanka.

Jayasekara, C., Ranasinghe, C.S. and Mathes, D.T. (1993). Screening for high yield and drought tolerance in coconut. In Advances in Coconut Research and Development. Eds. M. K. Nair, H. H. Khan, P. Gopalasundaram and E.V.V. Bhaskara Rao. 209-218. Oxford and IBH Publishing Co. Pvt. Ltd., New Delhi.

Lawlor D.W. (1995). Photosynthesis, productivity and environment. Journal of Experimental Botany 46, 1449-1461.

Liyanage, D.V. (1961 a). The use of isolated seed gardens for coconut seed production. Ceylon Coconut Quarterly 12, 245-252.

Liyanage, D.V. (1961 b). Annual Report of Coconut Research Institute of Sri Lanka for 1961. Ed. Salgado M.L.M. 33-36. Coconut Research Institute, Sri Lanka. 
Liyanage, M. de S. (1999). A guide to scientific cultivation and management of coconut. 1-10. Hitech Prints, Nugegoda, Sri Lanka.

Long, S.P., Zhu, X., Naidu, S.L. and Ort, D.R. (2006). Can improvement in photosynthesis increase crop yields? Plant Cell and Environment 29,315-330.

Mann, G.C. (1999). Crop scientists seek a new revolution. Science. 283: 310314.

Medrano, H., Keys, A.J., Lawlor, D.W., Parry, M.A.J., Azcon-Bieto, J. and Delgado, E. (1995). Improving plant production by selection for survival at low $\mathrm{CO}_{2}$ concentrations. Journal of Experimental Botany 46, 1389-1396.

Mitchell, R. A. C., Black, C. R., Burkart, S., Burke, J. I., Donnelly, A., de Temmerman, L, Fangmeier, A., Mulholland, B. J., Theobald, J. C. and van Oijen, M. (1999). Photosynthetic responses in spring wheat grown under elevated $\mathrm{CO}_{2}$ concentrations and stress conditions in the European, multiple-site experiment 'ESPACE-wheat'. European Journal of Agronomy 10: 205-214.

Nainanayake, A.D. (2004). Impact of drought on coconut (Cocos nucifera L.): screening germplasm for photosynthetic tolerance in the field. 44-45 p. PhD Thesis. University of Essex, UK.

Nainanayake, A.D. and Morison, J. I. L. (2004). Screening of coconut germplasm for drought tolerance based on physiological traits. 58-76 p. Eds. Peiris T. S. G. and Ranasinghe C. S. Proceedings Part II, International Conference, Coconut Research Institute of Sri Lanka.

Perera, L., Peries, R.R.A. and W.M.U. Fernando. (1996). Conservation of coconut (Cocos nucifera L.) biodiversity in Sri Lanka. Plant Genetic Resources Newsletter. 106: 1-4. 
Ranasinghe, C.S., Nainanayake, A., Gunawardena, M., de Saram, P.S.A. and Jayathilake, A. (2003). Report of the Plant Physiology Division In Report for 2003. Eds. Jayasekara, C, Everard, J.M.D.T, Appuhamy, P.H.A.N, Idirisinghe, I.M.S.K. 181-183. Coconut Research Institute, Sri Lanka.

Somasiri, L.L.W., Nadarajah, N., Amarasinghe, L., Gunathilake, H.A.J. (1994). Land suitability assessment of coconut growing areas in the coconut triangle. 1-7 p. Coconut Research Institute, Sri Lanka.

Vidhana Arachchi, L.P. (1998). Preliminary requirements to design a suitable drip irrigation system for coconut (Cocos nucifera L.) in gravely soils. Agricultural Water Management 38: 169-180.

Wachira, F., W. Ng'etich, J. Omolo, G. Mamati. 2002. Genotype x environment interactions for tea yields. Euphytica. 127: 289-296.

Wickramaratne, M.R.T. (1984). Report of the Genetic and Plant Breeding Division In Report for 1984. 45-46. Eds. Wettasinghe, D.T. and Mahindapala, R. Coconut Research Institute, Sri Lanka. 